\title{
EXPERIMENTAL STUDY OF SUPERSONIC JET CHARACTERISTICS OF A GROOVED NOZZLE
}

\author{
KOWSALYA $\mathbf{P}^{\mathbf{1}}$, ASHWIN V.G ${ }^{2}$, DHARANI $\mathbf{J}^{\mathbf{3}}$ \& SURESH CHANDRA KHANDAI ${ }^{4}$ \\ ${ }^{1,2}$ Research Scholar, Department of Aeronautical Engineering, Rajalakshmi Engineering College, Chennai \\ ${ }^{3}$ Assistant. Professor, Department of Aeronautical Engineering, Rajalakshmi Engineering College, Chennai \\ ${ }^{4}$ Associate Professor, Department of Aeronautical Engineering, Rajalakshmi Engineering College, Chennai
}

\begin{abstract}
In this paper, an investigation is done for supersonic jet expanding from convergent-divergent nozzle with and without grooves for three different conditions such as over expansion, optimum expansion and under expansion. A convergentdivergent $(C-D)$ nozzle was designed for Mach number of 1.4 with exit diameter of $12 \mathrm{~mm}$. Flow visualization technique was used to visualize shocks at the exit of nozzle with help of shadowgraph method. Experiments were conducted and pressure decay tests were taken for three different cases. Core length was also found with the help of pressure decay test. The changes and effects of jet mixing enhancement for nozzle with and without grooves in three different cases were studied experimentally in this project. A new type of groove geometry is introduced in the nozzle core flow and the effects of potential core length, shock cell, Mach disk were studied.

KEYWORDS: Supersonic Jet, Grooved Nozzle, C-D Nozzle, Nozzle Pressure Ratio
\end{abstract}

Received: Jun 08, 2020; Accepted: Jun 28, 2020; Published: Aug 19, 2020; Paper Id.: IJMPERDJUN2020819

\section{INTRODUCTION}

Development in Aerospace industries has lead to an intense development in the design and parameters of the nozzle section. Different types of nozzle has been designed, tested and used in different areas. The most commonly encountered problem in any nozzle will be its entrainment character of the exit jet. Better entrainment character of the nozzle will lead to weaken the shock cell formed. In order to increase the entrainment character, different technique has been adopted by different researchers and were studied. One among the different technique is the implementation of internal grooves. These internal grooves are designed in different shape and dimensions. In this paper a truncated square groove at the end of the diverging section has been imparted and tests were carried out to study the entrainment character.

Many researches and computational analysis were carried out for different tab geometries, tabs with perforations $[9,10]$ and grooved nozzle to study the decay characteristics. The decay characteristics of supersonic jets issuing from a circular nozzle with square grooves for three different total pressures were studied by Ilakkiya et al. The presence of single and double grooves at lower pressure values is more effective than at higher pressure. Double grooved nozzle shows better entrainment character than the single grooved nozzle [1]. A computational analysis has been carried out to study the flow deployment from a circular supersonic jet issuing from nozzle with and without triangular grooves. When the grooves are introduced, the rapid decay in the supersonic jet comes earlier than nozzle without groove [2]. A new semicircular shaped groove was designed and experimental studies 
were done. It was found that the jet decay character was improved compared to that of the plain nozzle. Off centre peaks were observed because of the formation of the stream wise vortices shed from the groove[3]. The aerodynamic and acoustic characteristics of jets from nozzles with internal grooves were studied and compared for semicircular and square groove. It is observed that in semi-circular grooved nozzle, first two shock cell characters are similar to that of plane nozzle and the decay is rapid only after the fourth shock cell. Square grooves influences the shock cell strength form the first cell. Thus square groove has better entrainment character than semi circular groove [4].

The next phase of the propulsion system is the hypersonic vehicle. These hypersonic vehicles mostly uses the rectangular nozzle for design simplicity. Many research work has been conducted in this sector of the nozzle for entrainment character. A Computational study has been carried out in rectangular nozzle with square grooves. The grooves were made for three different orientations as minor- axis, major-axis and in both minor and major axes. Potential corelength of plain jet and jet with grooves in major axis direction extends up to $3 \cdot 9$ times of the exit diameter of the nozzle (D). On the other hand, for jets with grooves in minor-axis direction and in both axes, the potential core-length extends up to 4D [5]. Nozzle with semicircular groove and square groove were constructed and results were compared .It is clear from the experiment that the square groves has more effect on the nozzle jet decay character compared to that of the semi circular grooves. This grooves results in the formation of screech with lower amplitude and higher frequencies [6].

\section{DESIGN AND GEOMETRY}

For the study two nozzles were fabricated, one single grooved nozzle and one double grooved nozzle, for the required dimension of $12 \mathrm{~mm}$ exit diameter and area ratio $\left(\mathrm{A}_{\mathrm{e}} / \mathrm{A}_{\mathrm{t}}\right)$ of 1.115 (as shown in Figure 1). The nozzle was designed with the help of Catia V5 and was fabricated in order to operate at a exit Mach number of 1.4. Truncated square grooves were introduced at the exit of the nozzle towards the throat up to a distance of $12.5 \mathrm{~mm}$ i.e., half the diverging length. The dimensional cross section view of the nozzle is shown in Fig 1.The figure 1(b) and 1(c) shows the dimension and placement of single groove and double groove atthe exit of the nozzle

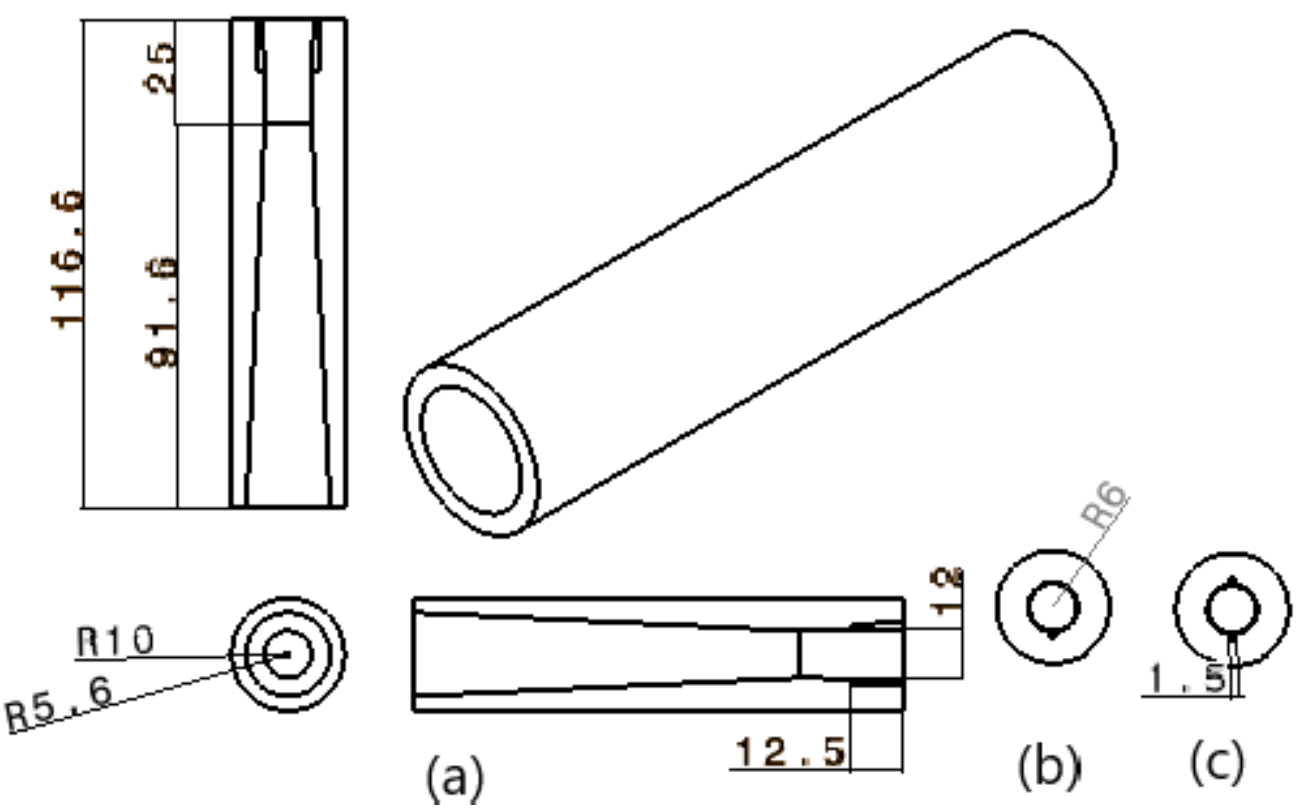

Figure 1: Three View Diagram of Plain and Grooved Nozzle. 
The Nozzle Pressure Ratio(NPR) for optimum expansion was set as 3.25bar. The under expanded and over expanded condition's NPR were set as 5bar and 2.25bar respectively.

\section{EXPERIMENTAL SETUP}

\section{High Speed Jet Facility}

All the experiments were carried out at the high speed jet facility present at the Department of Aeronautical Engineering (REC), Rajalakshmi Engineering College, Chennai, India(Figure 2). The reservoir has a maximum capacity of 25 bar.A two $15 \mathrm{hp}$ compressors were used to charger the reservoir. The compressed air from the reservoir was supplied to the settling chamber with the help of a rubber house. The settling chamber has a opening valve and a pressure regulating valve in it. A pressure gauge, which can read up to $30 \mathrm{bar}$ was installed in it. The traverse mechanism was used to hold the Pitot tube and move the Pitot tube in axial distance at uniform speed. A eight channel pressure transducer was used to measure the pressure readings. A laptop with data accusation board was used to extract the values form the transducer.

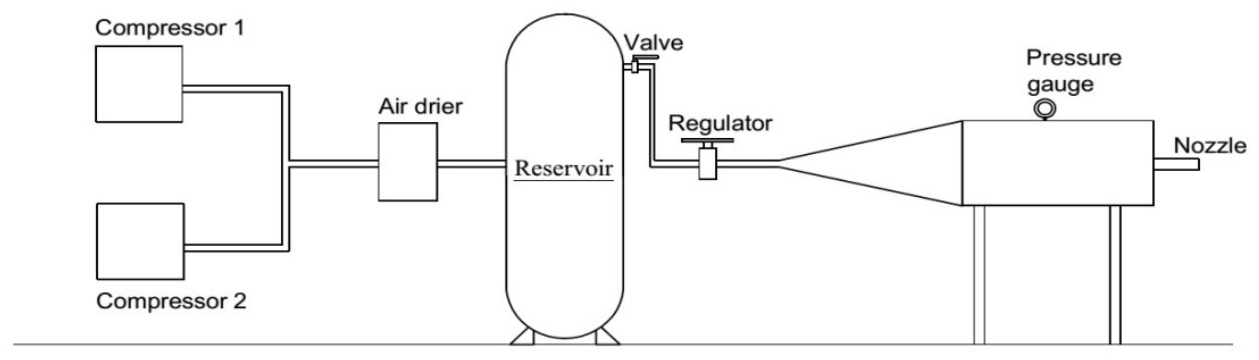

Figure 2: Schematic Diagram of Supersonic Jet Test Facility at REC.

\section{Flow Visualization}

Flow visualization techniques are used in order to view the density variation in a gaseous medium. A single mirror and single lens Shadow graph flow visualization technique was used in order to capture the shock pattern of the nozzles. The surface of the mirror was covered and a small hole of $10 \mathrm{~cm}$ diameter was made in order to focus the light on to the screen. A convex mirror was used in order to focus the light on to the mirror. Sodium vapour lamp was used as a monochromatic light source. The images were captured using a 22mega pixel DSLR camera.

\section{RESULTS AND DISCUSSIONS}

The experiments were carried out for optimum-expansion, under-expansion and over-expansion conditions. The pressure values are 5 bar, 3.25 bar,2.25 bar for under-expansion, optimum-expansion and over-expansion respectively. Core length is the main factor on which the whole experimentation is related to. The core length determines the entrainment character of a nozzle jet. For the jet to be of more entrained then the core length must be as small as possible. In this paper three condition were taken into consideration and experiments were carried out for plain nozzle, one grooved nozzle and two grooved nozzle.

The nozzle exit jet character was studied by measuring the total pressure along the centre line of the downstream of the nozzle jet. Faster entrainment results in faster mixing of the exit jet with the ambient air. Thus the total pressure readings were used to measure the character of both the grooved and un-grooved nozzle. The jet portion were the flow is supersonic in nature is highly wave dominant in nature. 
The centre line total pressure measurements were taken for three different inlet condition for three different nozzle. In order to plot the graph the readings were converted to non dimensional units such as $\mathrm{P} / \mathrm{P}_{\mathrm{o}}$ for the pressure values and X/D for the distance values. The figure 3(a),3(b)and 3(c) shows the centre line pressure values for the three different cases such as under expansion, over expansion and optimum expansion respectively. In figure3(a) the pressure values starts to reduce and then the line starts to increase, this is because the first wave present in the exit of the nozzle in under expansion is a expansion wave and in expansion the pressure value starts to reduce before the expansion fan and then the pressure value increases after the fan. In figure3(c) optimum expansion also shows the same type of wave pattern seen in under expansion and this is because the optimum expansion case value acts as the under expansion case in real time. In over expansion the inlet pressure in very low due to which the pressure graph tends to move in a straight line.

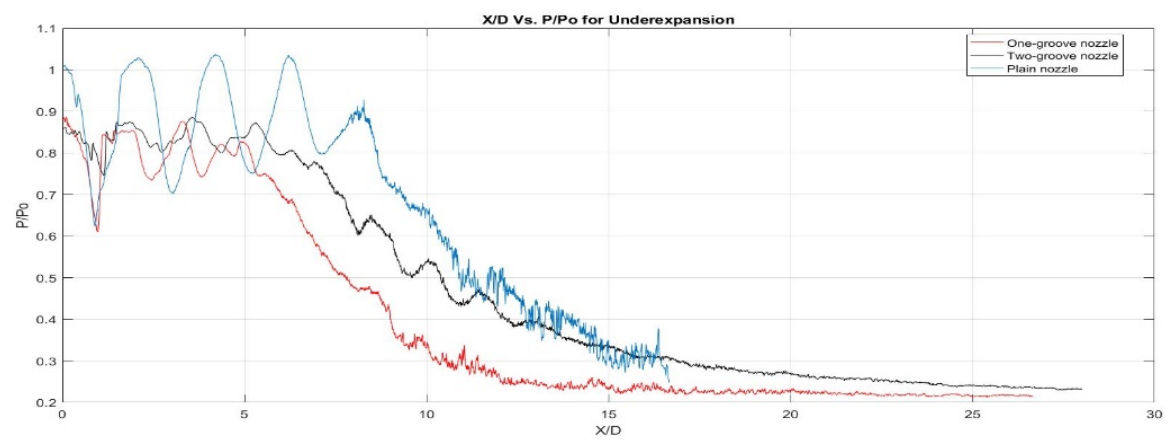

Figure 3(a): Comparison of Centerline Pressure Decay for Under Expanded Nozzles.

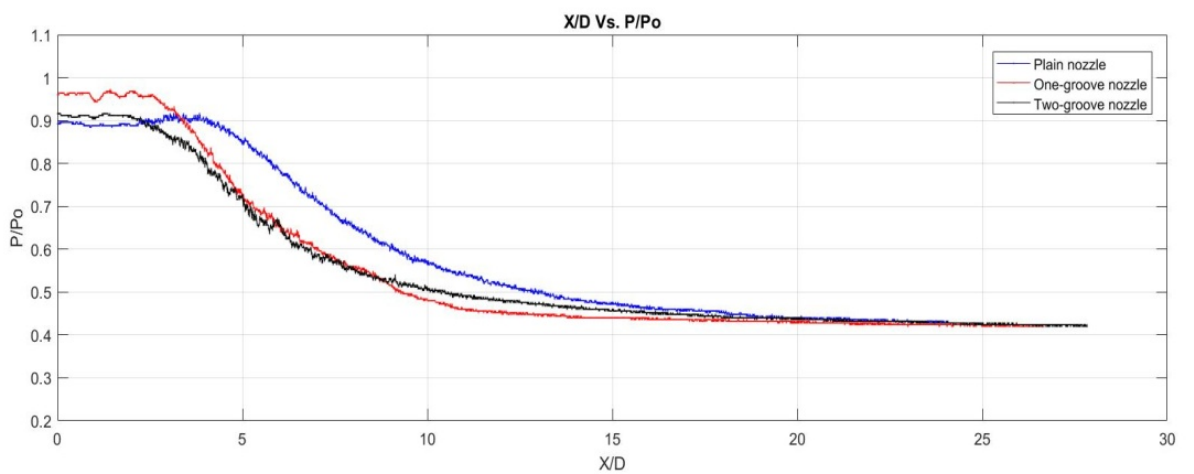

Figure 3(b): Comparison of Centerline Pressure Decay for Over Expanded Nozzles.

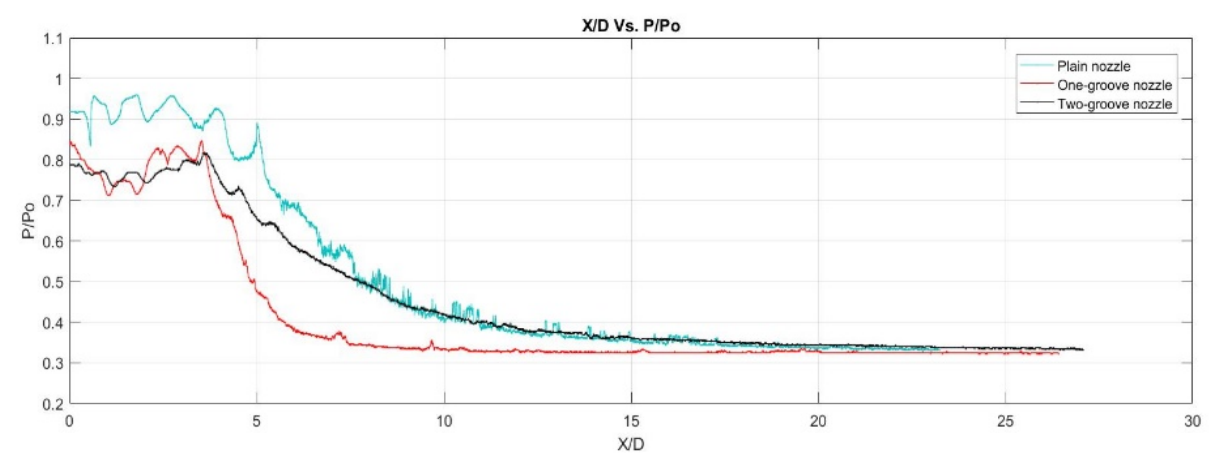

Figure 3(c): Comparison of Centerline Pressure Decay for Optimum Expanded Nozzles. 
In case of under expansion, the plain nozzle has a core length of $8.2 \mathrm{D}$ where as in the case of single grooved and double grooved nozzle has a core length of 6.37D and 5.48D respectively. This reduction in core length is caused by the formation of vortices in the exit of the nozzle. When the jet moves from throat to exit of the nozzle it experiences an increase in the exit area this is due to the presence of the grooves. In single grooved nozzle increase in area is within the allowable region which makes the groove as standard one. This case is applicable for the double groove case also.

The groove tends to increase the exit area. This increase in the exit area causes a sudden expansion in the jet. This expansion causes the jet to deviate from the centre line to outward direction. This deviation of the jet causes the outer layer of the jet to mix with the ambient air from the start of the exit of the nozzle. This mixing is known as the turbulence in the exit jet. This turbulence weakens the strength of the shock cell. This weak shock cell tends to have a god mixing character with the ambient air.

As the inlet pressure reduces, the core length of the nozzle exit jet also reduces. This can be seen in the case of over expansion were the plane nozzle has a core length of 4D, single groove has a core length of 2.78D and double groove has a core length of 2.14D. This signifies that the reduction in the core length with the grooves is less effective at lesser inlet pressure. This is because at the low inlet pressure the velocity of the air moving will also be less. This less velocity air does not create a faster vortex and thus the turbulence created is small and hence the core length of the exit jet also does not reduce in a much appreciable value.
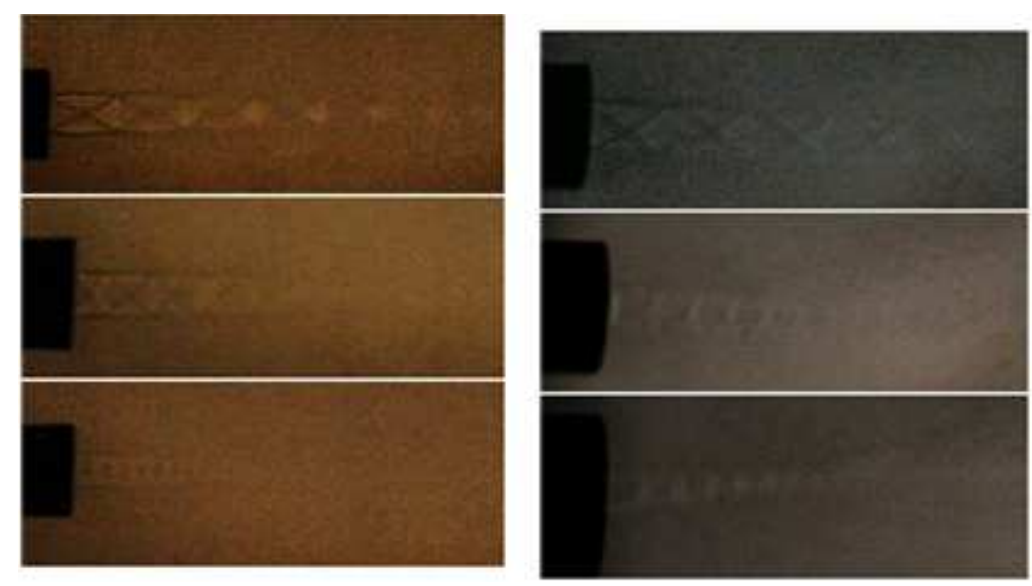

Figure 4: (a) (b) (c)

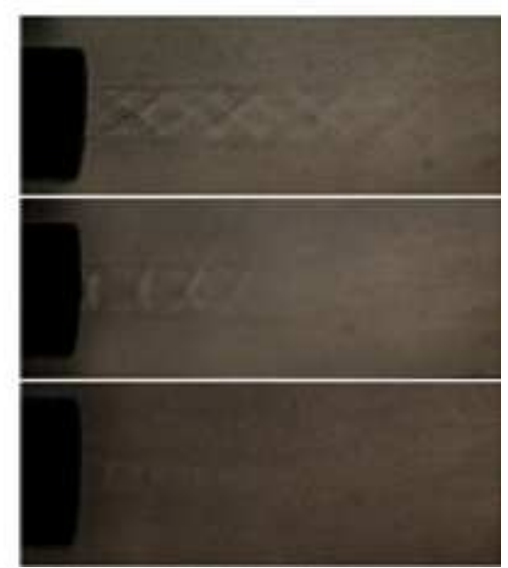

The shadowgraph method of flow visualization technique was used to capture the flow patterns at the exit of the nozzle. Figure 4(a) shows the shocks at the exit of plain nozzle for three cases. The upper part was under expansion, the middle part was optimum expansion and the lower part was overexpansion. Similarly, figure4(b) shows one-grooved nozzle and figure4(c) shows two-grooved nozzle. As seen in figure4(b), the jet boundary was not straight as compared to plain nozzle because a one-groove was introduced in nozzle, hence the flow was asymmetric. When groove was introduced at the exit of the nozzle, the area of exit would be increased, this lead would weak the shocks at the exit of the nozzle. Hence at figure4(c) for overexpansion case, the shocks were not clearly visible.

\section{CONCLUSIONS}

In this experimental work, the effect of truncated square groove in circular nozzle was investigated for three cases such as under expansion, optimum expansion and over expansion. The pressure decay test shows that at under expansion case the core length with one-groove was reduced by $22.3 \%$ and with two-groove was reduced by $33.17 \%$. This shows that two- 
groove is more effective in under expansion case. For optimum expansion the core length for one groove was reduced by $27 \%$ and for two-groove the core length reduced by $26.7 \%$. This shows that there is not much difference in one-groove and two-groove in optimum expansion case. For over expansion case the core length for one-groove is reduced by $30.5 \%$ and for two-groove the core length was reduced by $46.5 \%$. Hence, this shows that two-groove is more effective than onegroove in over-expansion.

\section{NOMENCLATURE}

- X Distance along the axis of the nozzle

- C-D Convergent-Divergent

- NPR Nozzle pressure ratio

- D Exit diameter

- P Pressure measured by Pitot tube

\section{REFERENCES}

1. S.Ilakkiya and T.N.sridhar (2018), "An experimental study on the effect of square groove on decay characteristics of a supersonic jet from a circular nozzle"," Journal of Mechanical Science and Technology", vol. 32, pp. 4721-4729.

2. Dominic Xavier.D and R.Sarath Kumar (2017) " Decay characteristics of supersonic jet issuing from c-d nozzles with triangular grooves", "International Journal of Mechanical Engineering and Technology", vol. 8, pp. 449-456

3. Rathod, Chandar., and Gondi Konda Reddy."Experimental investigation of angular distortion and transverse shrinkage in CO2 arc welding process." International Journal of Mechanical Engineering, 5 (4), 2128 (2016).

4. S.Elangovan and Rathakrishnan (2004)"Studies on high speed jets from nozzle with internal grooves","The Aeronautical journal", pp. 2819-2826

5. Ahamed Saleel C.and Mohammad Jamil Ahmad (2005),"Supersonic jet control with internal grooves", "International Conference on Mechanical Engineering", vol. 28, pp. 15-20.

6. Ayyappan, A., et al. "Influence of Geopolymers in the Stabilization of Clay Soil." International Journal of Emerging Technologies in Engineering Research (IJETER) Volume 5 (2017).

7. M Sundararaj and S. Elangovan(2013),"Computational analysis of mixing characteristics of jets from rectangular nozzle with internal grooves", "Indian Journal of Science and Technology", vol. 6, pp 4543-4548.

8. Jayanth Vishnu and E.Rathakrishnan(2004), "Acoustic characteristics of supersonic jets from grooved nozzles","Journals of Propulsion and Power", vol. 20, pp. 520-526.

9. Kanth, Tn Ravi, Sudhakara Reddy Kalavapalli, and B. Phani Kumar."Performance Evaluation of VCR Ci Engine Using CD Intake Manifold With Internal Grooving."International Journal of Mechanical and Production Engineering Research and Development (IJMPERD) 8. 1, Feb 2018, 319- 326

10. Mrinal Kaushik and Prashanth Reddy Hanmaiahgari (2015),"Effects of Under Expansion Level on Sonic Turbulent Jets Propagation", "American Journal of Fluid Dynamics", vol. 5(3A), pp. 12-18.

11. P. Arun Kumar. S. B. Verma and S. Elangovan (2011),"Study of jets from rectangular nozzles with square grooves","The Aeronautical Journal", vol. 115, pp. 3593-3602. 
12. Ezhilmaran, G., Suresh Chandra Khandai,Pavithrabalan, S., Udhayakumar K.,(2018) "Supersonic Jet Control by Tabs with Slanted Perforation", " International Journal of Turbo \& Jet-Engines", doi:10.1515/tjj-2018-0034.

13. Shaik, Bazani, G. HarinathGowd, and B. Durga Prasad. "An Optimization and Investigation Of Mechanical Properties and Microstructures On Friction Stir Welding Of Aluminium Alloys." International Journal of Mechanical and Production Engineering Research and Development (IJMPERD), ISSN (P): 2249-6890.

14. Ezhilmaran, G., Suresh Chandra Khandai,Yogesh Kumar Sinha., Thanigaiarasu S., $\quad$ (2019) "Numerical Simulation of Supersonic Jet Control by Tabs with Slanted Perforation", "International Journal of Turbo \& Jet-Engines”, doi: 10.1515 /tjj2019-0015. 

